\title{
Metastatic Malignant Neoplasm in the Bone
}

National Cancer Institute

\section{Source}

National Cancer Institute. Metastatic Malignant Neoplasm in the Bone. NCI Thesaurus.

Code C3580.

The spread of a malignant neoplasm from a primary site to the skeletal system. The majority of metastatic neoplasms to the bone are carcinomas. 